\title{
COMUNICAÇÕES
}

\section{CONSIDERAÇÕES SOBRE A INFLUÊNCIA DA ANÁLISE DAS DEMONSTRAÇÕES NO CICLO DO PEDIDO LOGÍSTICO - ANÁLISE DO CASO ATOFINA BRASIL*}

\author{
Angélica do Espírito Santo** \\ Mestra em Controladoria e Contabilidade pela FEA-USP \\ E-mail: asanto@t-gestiona.com.br
}

\section{RESUMO}

O principal objetivo deste estudo consistiu em identificar a influência da análise das demonstrações contábeis utilizadas no processo de estabelecimento do limite de crédito a um cliente, no ciclo do pedido logístico.

Para a consecução deste trabalho, foi realizado um estudo de caso, de caráter descritivo, na Atofina Brasil, empresa do setor químico.

Verificou-se, pelo estudo de caso, que o analista de crédito utiliza diversas fontes de informações como meio de subsidiar o processo decisório de estabelecimento do limite de crédito, sendo uma delas as demonstrações contábeis.

Com relação às demonstrações contábeis no ciclo do pedido da Atofina Brasil, foi verificado que o período de tempo necessário para a análise de crédito não está relacionado à qualidade das informações contábeis. Isso porque o analista de crédito considera que as demonstrações contábeis apresentam adequadamente a situação econômico-financeira da empresa.

Palavras-chave: Demonstrações contábeis, análise de crédito, ciclo do pedido, processamento do pedido.

\section{ABSTRACT}

This study aimed to identify the influence of financial statement analysis, used in the process of establishing customer credit limits, as a part of the logistic order cycle.

Thus, a descriptive case study was carried out at Atofina Brazil, a company in the chemical industry.

On the basis of this case study, we observed that the credit analyst uses various information sources as a support in process of deciding about credit limit establishment, one of which are financial statements.

With respect to the impact of financial statements on the order cycle of Atofina Brazil, it was verified that the time period needed for the credit analysis process is not related to accounting information quality, because the credit analyst considers that financial statements offer an adequate representation of the company's economic and financial situation.

Keywords: Financial statements, credit analysis, order cycle, order processing.

\footnotetext{
* Artigo baseado na Dissertação de Mestrado intitulada "Considerações sobre o papel das demonstrações contábeis no processo de estabelecimento de limites de crédito, como parte do processamento de pedidos”, sob orientação do Prof. Dr. Masayuki Nakagawa, apresentada ao Departamento de Contabilidade e Atuária para obtenção do Título de Mestre em Controladoria e Contabilidade pela Faculdade de Economia, Administração e Contabilidade da Universidade de São Paulo.

** A autora agradece à Atofina Brasil, empresa que permitiu a elaboração deste estudo de caso, principalmente, a: Mônica Cappelli, gerente de logística, Milton Lopes, assistente de logística e Cláudio de Araújo Lima, analista de crédito, por suas inestimáveis colaborações.

Recebido em $07.05 .03 \cdot$ Aceito em $23.10 .03 \cdot 2^{\text {a }}$ versão em 10.11 .03
} 


\section{INTRODUÇÃO}

O objetivo básico da Contabilidade, como preceituado por ludícibus (1997:22), é o de prover os usuários das demonstrações contábeis com informações que os apóiem no processo de tomada de decisões econômicas, sejam elas operacionais, de financiamento ou de investimento. O credor, por exemplo, estaria interessado em que a Contabilidade pudesse fornecer indícios com relação à geração de fluxos de caixa futuros suficientes pelos seus clientes, de modo que eles fossem capazes de honrar os compromissos assumidos, com segurança.

O analista de crédito, ao utilizar informações contábeis como meio de subsidiar o processo de avaliação de risco de crédito, deve atentar também ao fato de que essa atividade se encontra inserida no contexto da cadeia de suprimentos, em que a logística deve criar utilidade de lugar e tempo para os clientes, em um ambiente de extrema complexidade e competitividade.

Christopher (1997:138) explica que:

Sob o ponto de vista do cliente, existe apenas um prazo: o tempo decorrido desde a entrega do pedido até a entrega do produto. Certamente, esta é uma variável competitiva à medida que um número cada vez maior de mercados está se tornando mais competitivo em relação ao tempo. Entretanto, isto representa um ponto de vista parcial a respeito de prazo. Tão importante quanto, agora sob a ótica do fornecedor, é o tempo decorrido entre a transformação de um pedido em caixa que, na realidade, é o tempo total em que o capital de giro fica comprometido, desde a aquisição dos materiais até o pagamento pelo cliente.

Informações acuradas são fundamentais para o modelo decisório do analista de crédito, de modo que ele possa atingir os objetivos precípuos da análise de crédito, quais sejam os de identificar os riscos nas situações de crédito, evidenciar conclusões quanto à capacidade do cliente em honrar sua dívida e fazer recomendações relativas à melhor estruturação de crédito a conceder, tendo em perspectiva a maximização dos resultados da empresa.

Apesar de amplamente discutida na literatura de análise de crédito a utilização de informações extraídas das demonstrações contábeis para apoiar as decisões de crédito, no entanto, verifica-se uma lacuna no que se refere ao papel das informações contábeis no processo de definição do limite de crédito, como parte do processamento do pedido e a identificação de influências no tempo de consecução do mesmo.

O objetivo da pesquisa a ser realizada, por meio deste trabalho é identificar a influência das demonstrações no processo de estabelecimento do limite de crédito, no tempo do processamento do pedido, e, por conseqüência, no ciclo do pedido (CP).

O ciclo do pedido do cliente inclui o tempo decorrido entre a colocação do pedido até o seu recebimento nos estoques do cliente. Analisar-se-á somente a parte do ciclo do pedido interna à empresa, isto é, o espaço de tempo decorrido desde o recebimento do pedido até sua expedição para o cliente (carregamento do caminhão), focalizando, sobretudo, o tempo demandado pela atividade de análise de crédito. Como mostra a Figura 1, a atividade de análise de crédito é parte integrante do processamento do pedido, tendo como um dos seus escopos principais de trabalho o estabelecimento do limite de crédito de um cliente, o qual possibilitará ou não a consecução da venda a prazo.

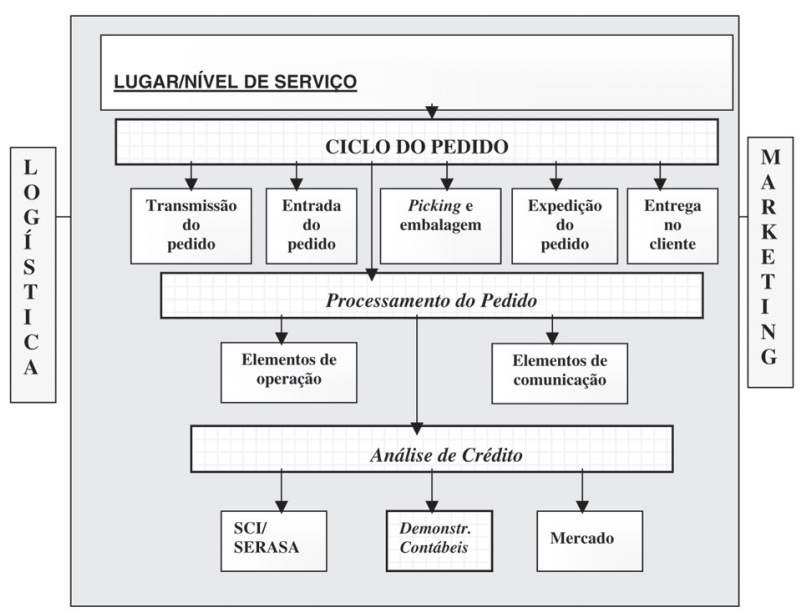

Fonte: Adaptado de Lambert et al. (1998).

Figura 1 - A Atividade da Análise de Crédito
no Contexto de Logística Integrada

A hipótese geral que orienta o presente trabaIho é a de que a análise das demonstrações contábeis utilizadas na atividade de estabelecimento do limite de crédito, como parte do processamento do pedido, poderia influenciar no ciclo do pedido, de modo que poderia aumentá-lo de forma significativa, devendo 
ser analisada a veracidade de tal assunção. Com vistas a testar a hipótese, foi conduzido um estudo de caso na Atofina Brasil, concentrando-se as análises na variável $A_{3}$, a qual representa o tempo demandado para os elementos de crédito que se consubstanciam no processo de análise, estabelecimento e liberação de crédito.

Assim, o método adotado é o monográfico. Segundo Gil (2000:42), “o método monográfico fundamenta-se no estudo aprofundado de um caso considerado representativo de muitos outros ou mesmo de todos os casos semelhantes".

Adotou-se o estudo de caso como estratégia de pesquisa posto que, nesse trabalho, diferentemente de uma pesquisa elaborada por meio de levantamento, havia a necessidade de se lidar com questões contextuais inerentes à utilização das demonstrações contábeis no processo de estabelecimento do limite de crédito, como parte do processamento de pedidos de uma organização específica.

Dessa forma, o estudo de caso foi considerado o melhor método para atender aos propósitos da pesquisa, haja vista que conforme explica Yin (1989:13) "caracteriza-se por se tratar de um estudo empírico em que é investigado um fenômeno atual dentro de seu contexto real".

O estudo de caso foi utilizado de modo descritivo, buscando associações entre o uso de demonstrações contábeis na análise de crédito e o do ciclo do pedido.

A Atofina Brasil foi a empresa escolhida para se proceder ao estudo de caso, posto que apresentou as características necessárias para se estar procedendo ao estudo, ou seja, empresa cujos clientes são pessoas jurídicas, utilizando demonstrações contábeis como fonte de informação para análise de crédito, atuando num contexto de cadeia de suprimentos, em que a logística é um fator de estratégia competitiva ${ }^{1}$. Adicionalmente, a empresa mostrou-se interessada em colaborar com a realização do estudo de caso, o que demandava o esclarecimento de seus procedimentos internos, de cunho confidencial.

Dessa maneira, o foco dessa seção restringe-se à análise de crédito realizada por empresas para estabelecer um limite de crédito na venda a prazo aos seus clientes, que no caso serão apenas pessoas jurídicas, não abordando, dessa maneira, a análise de crédito feita especificamente pelo setor bancário, ou então às pessoas físicas.

\section{REVISÃO BIBLIOGRÁFICA}

\subsection{Principais aspectos da logística e ciclo do pedido}

Primeiramente, deve-se considerar que um fator crítico para o sucesso do gerenciamento da cadeia de suprimentos é a integração de todos os processos relativos às atividades operacionais de uma empresa, seus clientes e fornecedores.

Conforme Rutner e Langley (2000:73) "os setes C's define a logística como a garantia do produto certo, na quantidade certa, no condição certa, no lugar certo, na hora certa, para o cliente certo, ao custo certo" (tradução do autor).

Desse modo, a logística cria valor aos clientes, fornecedores e acionistas da empresa ao fornecer utilidade de tempo e de lugar na transferência de mercadorias e serviços entre o comprador e o vendedor, visto que não existe valor para produtos e serviços a menos que estejam nas mãos dos clientes quando (tempo) e onde (lugar) eles desejem consumi-los. Portanto, deve-se atentar para a velocidade e a confiabilidade na qual os itens pedidos pelos clientes tornam-se disponíveis a eles.

Bowersox (1996) explica que a velocidade e a precisão do processamento de pedidos estão atreladas ao nível de serviço ao cliente que é propiciado pela empresa, pois quanto mais tempo levar o ciclo do pedido, menor a satisfação do cliente e, conseqüentemente, menores poderão ser os lucros da empresa. Além disso, sob a perspectiva logística, serviço ao cliente é o resultado de todas as atividades logísticas visando a criar utilidade de tempo e lugar.

De acordo com Ballou (1993:40), a logística de distribuição está intimamente ligada ao marketing (produto, lugar - ou seja, distribuição física, preço e promoção). A demanda é obtida através do mix de produtos, preço e promoção. Para essa demanda ser atendida, o quesito lugar é fator primordial, sendo essa a responsabilidade da logística de distribuição. 
O ciclo de pedido do cliente, conforme conceituado por Lambert, Stock e Vantine (1998:518), inclui o tempo que se passa entre a colocação do pedido até o seu recebimento no estoque do cliente, consistindo, tipicamente, das seguintes etapas: (1) preparação e transmissão do pedido; (2) recebimento e entrada do pedido; (3) processamento do pedido; (4) resgate no estoque e embalagem; (5) expedição do pedido e (6) entrega e descarregamento no cliente.

Segundo Lalonde e Zinszer (1976: iv), os componentes das atividades de processamento de pedidos podem ser subdivididos em três grupos: (1) elementos operacionais, tais como: verificação de disponibilidade do produto, escalonamento, preparação para a expedição e faturamento; (2) elementos de comunicação, destacando-se alterações no pedido, consulta sobre situação, localização e velocidade do pedido, correção de erros e pedidos de informações; e (3) elementos de crédito como informações cadastrais, análise e limite de crédito.

De acordo com Ballou (2001: 82), os elementos do ciclo do pedido são o tempo de transmissão e processamento do pedido, o tempo de montagem do pedido, a disponibilidade de estoque, o tempo de produção e o tempo de entrega.

O processamento do pedido inclui atividades como: preparação de documentação de embarque, atualização de registros de estoque, coordenação de liberação de crédito, checagem de erros nos pedidos, comunicação com os clientes e partes interessadas dentro da empresa, situação de pedidos e disseminação da informação do pedido para vendas, produção e contabilidade.

Ballou (2001:114), ainda, explica que "as atividades de processamento de pedido podem representar a maior parte do tempo total do ciclo do pedido. Assim sendo, o gerenciamento das atividades dos componentes do processamento de pedido e do ciclo de pedido total é crucial para o nível de serviço ao cliente a ser alcançado"(grifos nossos).

Os clientes estão cada vez mais sensíveis ao tempo decorrido desde a entrega do pedido até a entrega do produto (tempo do ciclo do pedido). Isso enseja a necessidade de a empresa ponderar sobre a maior coordenação do processamento de pedidos até para haver maior confiabilidade na entrega.

\subsection{Análise de crédito e contabilidade}

Em consonância com o entendimento de Schrickel (2000: 25):

Crédito é todo ato de vontade ou disposição de alguém destacar ou ceder, temporariamente, parte do seu patrimônio a um terceiro, com a expectativa de que esta parcela volte a sua posse integralmente, após decorrido o tempo estipulado.

Dessa forma, a finalidade da análise de crédito é averiguar a adequação entre o crédito solicitado e a capacidade financeira do cliente em honrar tal dívida.

Segundo Silva (2000:104), o limite de crédito atribuído a um determinado cliente é o risco máximo que a empresa está disposta a correr com ele. Caso a empresa tenha uma política de liberação de crédito muito liberal, estará muito exposta aos riscos de seus clientes. Por outro lado, políticas de crédito muito rígidas podem provocar diminuições na venda, corroendo a lucratividade da empresa. Dessa forma, a empresa deve utilizar um parâmetro confiável como balizador de sua decisão de conceder ou não o crédito a um determinado cliente.

De acordo com Caouette, Altman e Narayanan (2000: 95), normalmente, são utilizadas as seguintes informações no processo de análise de crédito: (1) Ficha cadastral; (2) Demonstrações contábeis; (3) Relatórios de crédito com o histórico de pagamento do cliente junto a outras empresas; (4) Bancos; e (5) Experiência de pagamento do cliente com a própria empresa.

Tais informações visam a nortear a decisão a ser tomada pelo analista de crédito de maneira a propiciar uma decisão melhor alicerçada.

Além disso, conforme Gamble (2002:19), em pesquisa realizada pela Credit Research Foundation, foi constatado que, para $45 \%$ dos analistas de crédito que participaram daquela pesquisa, as demonstrações contábeis do cliente representavam a principal fonte de informação para decisões de crédito.

No concernente à análise econômico-financeira da empresa, pode-se utilizar uma série de metodologias a fim de se identificar o risco de crédito do cliente e sua capacidade de pagamento, dentre as quais Securato (2002) destaca: (1) Análise horizontal e vertical; (2) Índices financeiros convencionais, como os relacionados à lucratividade, 
à estrutura e à liquidez; (3) Fluxos de caixa e fluxos de recursos; (4) Investimento operacional em giro; (5) Capital de giro e capital permanente líquido; e (6) Modelos quantitativos.

Portanto, a Contabilidade deve gerar informações que proporcionem aos seus usuários, incluindo o analista de crédito, uma base segura para suas decisões, pela compreensão da situação econômico-financeira da empresa, seus riscos e oportunidades.

As qualidades básicas da informação contábil, quais sejam relevância, compreensibilidade, confiabilidade e comparabilidade, são fundamentais para torná-la útil aos seus usuários.

Tal informação deve ser imbuída de um caráter preditivo e divulgada, segundo Ikeda (2002), de acordo com o conceito de financial reporting, possibilitando que os usuários da Contabilidade tenham também acesso à informação de natureza não financeira, que seja relevante para o entendimento das operações da empresa e de suas demonstrações contábeis.

\section{ESTUDO DE CASO NA ATOFINA BRASIL}

\subsection{Considerações gerais}

Foi realizado um estudo de caso na ATOFINA Brasil, objetivando entender como a análise de crédito está inserida no contexto do ciclo do pedido e, mais especificamente, qual a influência da análise das demonstrações contábeis no ciclo do pedido da empresa.

O estudo de caso foi realizado utilizando-se um roteiro de pesquisa semi-estruturado, para coletar as evidências que pudessem fundamentar a análise do caso.

Foram conduzidas seis entrevistas na Atofina Brasil com duração média de duas horas cada uma, sendo duas com a gerente de logística, uma com a gerente de crédito e três com o analista de crédito, o qual ocupa a função de analista de crédito sênior na empresa. Desse modo, buscou-se levantar os fatos relevantes para a consecução do trabalho.

Além disso, vários documentos internos da empresa relativos aos processos de logística de distribuição e análise de crédito foram colocados à disposição pelos entrevistados, os quais forneceram informações adicionais sobre o caso em estudo, fundamentando as evidências encontradas.

\subsection{A Atofina Brasil}

A Atofina Brasil Química Ltda. é uma subsidiária da ATOFINA francesa e possui como ramo de atividade a industrialização e comercialização de produtos químicos, com um faturamento anual de aproximadamente $R \$ 110$ milhões em 2000 e $R \$ 124$ miIhões em 2001.

A Atofina Brasil está inserida num cenário bastante competitivo, em que a prestação de serviço e o atendimento ao cliente são diferenciais. Além disso, preço e condições de pagamento, assim como a qualidade do produto, são fundamentais para fidelizar um cliente.

A empresa se destaca nos segmentos químicos de resinas (fabricação no Brasil), odorantes, especificantes e poliamida (revenda de importados, principalmente).

Assim, os principais produtos comercializados pela ATOFINA Brasil são: resinas "commodities" e formol, resinas de especialidades, adesivos, peróxidos orgânicos, resinas sintéticas, elastômeros, cloreto de colina, polímeros, silicato de zircônio, produtos para metal e aviação e argilas descorantes.

A empresa, em 2002, possuía uma carteira de cerca de 500 clientes. Os principais clientes da Filial Jundiaí são: a Fras-Le S.A., Basf S.A., Satipel Minas Industrial Ltda., Rieter-ello Artefatos Fibras Têxteis Ltda., Foseco Industrial e Comercial Ltda. Já entre os clientes mais importantes para a Filial Rio Claro estão: a Clariant S.A., Calçados Azaléia S.A., Politeno S.A., Bayer Polímeros S.A. e Tintas Coral Ltda. Para a Filial São Paulo (Depósito Vergueiro) destacam-se os seguintes clientes: Springer Carrier S.A., Tecalon Brasileira de Auto Peças S.A., Valeo Sistemas Automotivos Ltda e Rhone Poulenc Agro Brasil Ltda. Finalmente, para a Filial Ananindeua os clientes de destaque são: a Eidai do Brasil Madeiras S.A., Brascomp Comp. Brasil S.A. e a Laminit S.A. Laminados e Comp.

\subsubsection{Processamento do Pedido}

O processamento do pedido enseja uma diversidade de tarefas nas várias áreas da empresa, tais como consulta de crédito, verificação de estoques, programação de transportes, embalagem, etc. 
Em geral, o ciclo completo do pedido ao cliente, considerando apenas o tempo demandado nas atividades internas da empresa para disponibilizar o produto ao cliente, incluindo tempo de preparação e transmissão do pedido, tempo de recebimento e entrada do pedido, tempo de processamento do pedido, de resgate do estoque e embalagem, tempo de expedição, com o seu faturamento e carregamento do caminhão, leva em média 24 horas, caso não seja a primeira venda a prazo. Ou seja, dentro dessas 24 horas médias não está contemplado o transporte até o cliente, que é função, basicamente, da localidade onde o mesmo se encontra e do tipo de transporte utilizado.

Quando o limite de crédito já foi anteriormente estabelecido por ter havido venda recente, a liberação de crédito leva, em média, uma hora, se não houver nenhum problema na revisão da situação econômico-financeira do cliente.

Em se tratando da primeira venda a prazo, o cliente deve enviar as demonstrações contábeis, ficha cadastral e referências para que o analista de crédito proceda ao estabelecimento do limite de crédito, obtendo também informações junto à SERASA ${ }^{2}$ e ao S.C.I. ${ }^{3}$ sobre a situação da empresa no mercado, bem como informações junto a bancos e fornecedores. Nessa situação, a análise de crédito leva até 48 horas, tempo estabelecido pela certificação ISO 9000, e o ciclo do pedido, excluindo o tempo de transporte até o cliente, completase em até 72 horas, com o carregamento do caminhão.

Conforme pesquisa realizada com 500 empresas do setor químico e petroquímico em esfera mundial, publicada em 2002, o tempo médio despendido para se realizar uma análise de crédito completa nos casos de primeira venda a prazo no setor químico é de 5 dias úteis (120 horas) ${ }^{4}$. Poder-se-ia indagar o porquê do tempo despendido na análise de crédito na Atofina Brasil é menos da metade da média do setor. Porém, o analista de crédito explica que a expansão de mercado, como o aumento do market share, é uma estratégia-chave para a empresa. Se não for possível atender o cliente rapidamente, ele irá comprar de outro fornecedor e a Atofina perderá vendas.

No caso de não haver demora no recebimento da documentação do cliente, bem como na confirmação de informações junto a bancos e fornecedores, a liberação de crédito na Atofina Brasil ocorre, em média, em 3 horas. De acordo com o entrevistado, a experiência do analista de crédito para analisar as demonstrações contábeis do cliente e demais informações, colaboram com a rápida e correta consecução do estabelecimento do limite de crédito a um cliente.

Contudo, em uma primeira venda a prazo, pode ocorrer atraso no estabelecimento do limite de crédito por dificuldade na obtenção de informações de mercado, como, por exemplo, demora na confirmação de informações junto a fornecedores, ou, ainda, demora na entrega de informações solicitadas pelo cliente, tais como composição dos sócios ou acionistas, fazendo com que haja um acréscimo de, no máximo, dois dias, além daquelas 48 horas estabelecidas. Não obstante, são situações raras e qualquer atraso é previamente negociado com o cliente.

O fluxo de informações para venda local, ${ }^{5}$ no caso da Atofina Brasil, tem início com o cliente contatando o encarregado de conta cliente para transmitir o pedido, geralmente via FAX ou telefone. Assim, o encarregado de conta cliente já verifica se o produto está disponível no estoque para a comercialização.

O encarregado de conta, ao receber o pedido, procede à sua entrada no sistema de processamento do pedido (plataforma AS400, isto é, sistema integrado de informações da empresa). Na primeira tela do sistema de pedido, são preenchidos os dados comerciais do cliente e na segunda, as informações sobre o produto.

Após serem completados todos os dados, é emitida, automaticamente (via sistema AS 400), uma mensagem informando que foi colocado um novo pedido, havendo emissão da boleta de crédito, sendo necessária a análise e/ou liberação ${ }^{6}$ de crédito para a autorização do despacho do produto para o cliente.

\footnotetext{
${ }^{2}$ SERASA - empresa que realiza análises e fornece informações econômico-financeiras e cadastrais, atuando com cobertura nacional e internacional. Maiores informações: $<$ www.serasa.com.br>.

${ }^{3}$ SCI - dispõe de informações comerciais sobre pessoas físicas e jurídicas no Brasil e exterior. Outras informações: www.equifax.com.br.

${ }^{4}$ Maiores informações sobre a pesquisa no site <www.heckett.com>. Os dados com relação a essa pesquisa foram obtidos em entrevista realizada com Sr. Rogério Neri Menezes, gerente financeiro da Rodhia, divisão Fios Têxteis, o qual participou do grupo de benchmarking, representando o setor químico do Brasil.

${ }^{5}$ No caso de venda local recorrente, em que é firmado um contrato de compras de longo prazo com o cliente, com todos os cronogramas de entrega, o comercial entra com o pedido nas datas previamente solicitadas pelo cliente no sistema de informações da Atofina Brasil (AS 400), contatando o cliente para informá-lo sobre a colocação do pedido.

${ }^{6}$ Em vendas recorrentes com limite de crédito atualizado, é necessária apenas a liberação de crédito.
} 
O pedido é, então, passado por FAX para a logística proceder às suas atividades, enquanto aguarda a aprovação de crédito. O departamento de crédito acessa os novos pedidos colocados para realizar sua análise e, eventualmente, quando um pedido é urgente, o próprio encarregado de contas telefona para o analista de crédito solicitando que acesse o AS400 para que tal pedido tenha seu crédito analisado preferencialmente.

Uma vez que o pedido colocado receba a liberação de crédito pelo departamento de análise de crédito, com a emissão do documento de "Liberação de Pedido para Faturamento" pelo sistema AS 400 da empresa, a logística consulta a situação do estoque e manda a Contabilidade faturar o pedido que, então, é expedido ao cliente.

\subsubsection{A análise de crédito na Atofina Brasil}

Para a liberação de créditos pedidos locais, a ATOFINA Brasil, utiliza, sobretudo, a análise de crédito feita internamente, conforme parâmetros estabelecidos por sua política de crédito, a qual recebeu certificação ISO 9000 em 1996.

Os procedimentos internos para a análise de crédito referentes à venda local para clientes são:

- Análise de restrições (S.C.I./Serasa/Mercado/ Análises de Demonstrações Financeiras/Informações sobre o Setor do cliente/ Pontualidade com a Atofina Brasil).

- Análise de Liberações, ou seja, se já houve alguma recusa anterior de concessão de crédito por parte da ATOFINA Brasil para aquele determinado cliente.

No caso de uma primeira compra do cliente na ATOFINA Brasil é necessário o envio de documentações, para que seja procedida a análise de crédito, visando ao estabelecimento do limite de crédito do cliente. Tais documentações incluem: a ficha cadastral, as referências bancárias e de fornecedores, principalmente, e as demonstrações contábeis do cliente. Para os clientes com os quais a ATOFINA Brasil já mantém um relacionamento comercial, as informações precisam ser anualmente reenviadas para atualização do cadastro.

As demonstrações contábeis exigidas das companhias abertas, clientes da ATOFINA Brasil, são aquelas publicadas anualmente, atendendo às exigências da Comissão de Valores Mobiliários (CVM), devendo, necessariamente, serem auditadas.

Já para seus clientes que são sociedades anônimas de capital fechado ou companhias limitadas, a empresa deve mandar as demonstrações contábeis assinadas pelo contador com o seu número do CRC, não necessitando, obrigatoriamente, serem auditadas. Porém, deve-se observar que, ocasionalmente, alguns clientes enviam as demonstrações contábeis sem assinatura do contador ou parecer dos auditores, ou ainda, deixam de enviá-las, por considerarem que seja um "luxo" desnecessário do fornecedor, fazendo com que a empresa tenha que recorrer a outras fontes, como o próprio SERASA, para obter as demonstrações.

Ocorre que, nem sempre, as demonstrações contábeis contidas no relatório SERASA se referem ao último exercício findo mais recente, prejudicando, parcialmente, as projeções que devem ser feitas através das demonstrações contábeis.

\subsubsection{Cenários na análise de crédito}

\section{Cenário 1 - Primeira Venda ao Cliente}

Uma primeira venda na Atofina Brasil, no geral, demanda um desenvolvimento do cliente por parte do vendedor, posto que os produtos da empresa tratam-se de químicos de especialidade, os quais devem ser compatíveis com o processo de fabricação do cliente. Desse modo, o vendedor deve fazer visitas ao cliente, enviando amostras ao mesmo para que seja verificada a qualidade e a compatibilidade do produto com os negócios do cliente.

Comumente, esse processo de desenvolvimento de um cliente para uma primeira venda leva em torno de cinco dias úteis.

Assim, enquanto o cliente está sendo desenvolvido pelo comercial, este já Ihe solicita informações gerais, de forma a possibilitar que o departamento de crédito desde logo proceda à uma pré-análise de crédito do cliente.

Quando o pedido é fechado, o vendedor, então envia para o departamento de crédito a ficha cadastral e o balanço de seu cliente para que seja completada a análise.

Assim, o departamento de crédito pede 48 horas para o estabelecimento de um limite de crédito que possibilite a liberação do crédito. 
As análises são feitas tomando-se por base as demonstrações contábeis do cliente, informações do SCI/SERASA e informações de mercado, bem como do setor do cliente.

\section{Cenário 2-Vendas recorrentes}

A liberação de crédito do cliente leva em média uma hora, quando se trata de uma venda recorrente em que não haja nenhum problema, pois apenas é necessário verificar alguma mudança cadastral da empresa e a situação de protesto, sendo preciso somente consultar as conclusões de uma análise das demonstrações contábeis do cliente previamente feita. Para análise da influência das demonstrações contábeis no processamento de pedidos, e como conseqüência, no ciclo de pedido, unicamente serão analisadas as situações de primeira venda, ou seja, clientes novos.

A análise de crédito é revisada anualmente, quando o cliente deve, novamente, enviar as informações necessárias (novo balanço, atualização da ficha cadastral, etc) para compor a sua pasta cadastral, estabelecendo-se o novo limite de crédito. Porém, semestralmente, é revisto o limite de crédito do cliente com base nas informações de mercado.

\subsubsection{Processo de estabelecimento do limite de crédito}

O limite de crédito atribuído a um determinado cliente é o risco máximo que a empresa está disposta a correr com aquele cliente. No caso da Atofina Brasil, o limite de crédito é estabelecido pelo analista de crédito, levando-se em consideração os seguintes parâmetros:

Indicadores de mercado

Ficha cadastral do cliente, a qual possui a relação dos principais clientes e fornecedores da empresa, seu faturamento, bancos com que mantém relacionamento, dentre outras. Com base nos dados enviados pelo cliente na ficha cadastral a empresa obtém:

- informações junto aos principais fornecedores a respeito de volume de compras, comportamento quanto aos pagamentos etc.

- informações junto aos bancos com que a empresa mantém relacionamento sobre sua capacidade creditícia.

- informações sobre a participação de mercado da empresa em análise.
Indicadores de setor

Indicadores específicos do setor do cliente, como perspectiva de crescimento, impacto de variáveis macroeconômicas no setor, tais como variação cambial e volatilidade da taxa de juros.

SERASA e SCI

Ficha SERASA e SCI, contendo informações com relação à situação de inadimplência do cliente junto ao mercado e demais riscos da empresa, calculados segundo parâmetros internos dessas empresas.

Indicadores econômico-financeiros extraídos das demonstrações financeiras

Análise das demonstrações financeiras visando à identificar a situação econômico-financeira da empresa. Em geral, é feita a análise vertical e horizontal, sendo calculados os índices de liquidez, lucratividade, endividamento, endividamento bancário e rotatividade. De acordo com o analista de crédito, a maior contribuição dos índices financeiros consiste no levantamento de uma série de questionamentos sobre a situação econômico-financeira da empresa, identificando pontos que demandam uma melhor investigação, que é feita através de informações de mercado e setor cliente.

Indicadores da situação do cliente junto à empresa, caso não seja a primeira compra a prazo

Valores acumulados de duplicatas a receber e verificação do histórico de pontualidade de pagamentos do cliente.

De posse dessas informações, o analista redige seu relatório de crédito para um determinado cliente, estabelecendo, com base também em seu julgamento pessoal e bom senso, um limite de crédito para ele, o qual será balizador da decisão de aprovar ou não o seu crédito.

Segundo a empresa, as informações contábeis respondem por $30 \%$ na decisão de estabelecimento do limite de crédito de um cliente, sendo esse o peso final das demonstrações contábeis no julgamento do analista de crédito, seguindo os preceitos determinados pela política de crédito da empresa, mediante observância dos critérios definidos pela certificação ISO 9000.

Além das demonstrações contábeis, a decisão de estabelecimento de limite de crédito pelo gestor é respaldada em $50 \%$ pelas informações de mercado e em $20 \%$ pelas demais informações, ou seja, setor, SERASA e SCI. 


\subsubsection{Decisão sobre liberação de crédito na Atofina Brasil}

No caso da Atofina Brasil, a decisão para liberação de crédito pode ser tomada apenas pela área de crédito ou, em situações excepcionais, pela área comercial. A seguir, é explicada cada uma dessas situações:

\section{Liberação de Crédito pelo Analista de Crédito}

Os parâmetros básicos para o estabelecimento do limite de crédito pelo analista de crédito, como já se mencionou, são os indicadores de mercado, indicadores setoriais, SCI e SERASA, indicadores econômico-financeiros extraídos das demonstrações financeiras e indicadores da situação do cliente junto à empresa, caso não seja a primeira compra a prazo. Em seu modelo de decisão, o qual é baseado em parâmetros técnicos, as informações de natureza contábil respondem por $30 \%$ do conjunto da decisão de estabelecimento do limite de crédito de um cliente.

Para ser estabelecido esse limite de crédito, o analista precisa do conjunto de informações retromencionadas para elaborar seu relatório de crédito. Vale ressaltar que, em uma primeira venda, o limite de crédito financeiro não é determinado, enquanto toda a documentação necessária não esteja disponível.

Após ter sido definido esse limite, o crédito de uma compra a prazo de um cliente é liberado automaticamente pelo analista de crédito até que se atinja esse teto e desde que o mesmo não tenha nenhum atraso em seu pagamento.

Liberação de Crédito pela Área Comercial

A liberação de crédito pela área comercial ocorre em situações específicas, dentre as quais destacam-se:

\section{Clientes novos: primeira venda ao cliente}

Falta de tempo hábil para o estabelecimento do limite de crédito pela área de crédito da empresa no caso de uma primeira venda ao cliente, devido à urgência de entrega de um produto.

Para que o analista de crédito possa estabelecer o limite de crédito, ele precisa ter reunido todas as informações preceituadas pelas normas de política de crédito da empresa. Em uma primeira venda, pode ocorrer o fato de que o cliente não tenha passado alguma informação relevante (como a ficha cadastral, informações da composição acionária da empresa), fazendo com que o analista de crédito não tenha todos os elementos necessários para compor sua análise, adequadamente.

Em geral, uma primeira venda na ATOFINA Brasil ocorre após uma estratégia de desenvolvimento do cliente pelo vendedor, que verifica cuidadosamente a participação de mercado dos concorrentes e o detalhe de consumo de seus clientes, selecionando aqueles clientes da concorrência que poderiam passar a compor a cartela de clientes da Atofina Brasil.

Uma possível insatisfação desse cliente no cumprimento do prazo firmado prejudicaria todo o trabaIho da área comercial em desenvolvê-lo, dificultando ou até mesmo impossibilitando a ocorrência de uma venda futura. Dessa forma, no caso do limite de crédito financeiro, o qual é estabelecido pelo departamento de crédito, não ter sido fixado dentro de 48 horas a partir da colocação do pedido, o crédito ao cliente é liberado pelo diretor comercial, com base em informações de mercado que ele dispõe sobre o novo cliente.

Um exemplo, que ilustra a importância de se ter esse procedimento alternativo, pode ser vislumbrado no caso General Motors (GM). A Atofina Brasil passou a ser fornecedora de um produto, 0 qual fazia parte do processo de produção de um dos modelos de automóveis da GM (o FORANE), que anteriormente vinha sendo fornecido pela Dupont. Porém, a empresa não passou toda a documentação para a análise de crédito em tempo hábil para que fosse estabelecido o limite de crédito pelo departamento de crédito da ATOFINA.

Uma vez que um atraso na entrega poderia criar um gargalo ou uma parada na linha de produção do cliente e até mesmo a perda de vendas futuras, o diretor comercial autorizou a liberação de crédito e, posteriormente, foi feita a análise de crédito financeira pelo departamento de crédito, quando chegou toda a documentação.

Em se tratando de uma primeira venda, o limite de crédito seria estabelecido e o crédito seria liberado unicamente pela área de crédito, se ao ocorrer um atraso por falta de informação ou no próprio processo de análise creditícia, o cliente concordasse em esperar um pouco mais para a expedição de seu produto. 


\section{A ANÁLISE DE CRÉDITO NO CONTEXTO DO PROCESSAMENTO DO PEDIDO E SUA INFLUÊNCIA NO CICLO DO PEDIDO}

Dada a descrição detalhada do processo de estabelecimento do limite de crédito da empresa analisada, é possível identificar esquematicamente que o ciclo do pedido (CP) pode ser encarado como função direta do tempo de preparação e transmissão do pedido $\left(X_{1}\right)$; tempo de recebimento e entrada do pedido $\left(X_{2}\right)$; tempo de processamento do pedido $\left(X_{3}\right)$; tempo de resgate do estoque e embalagem $\left(X_{4}\right)$; tempo de expedição $\left(X_{5}\right)$; e tempo de entrega e descarregamento no cliente $\left(X_{6}\right)$.

Assim, $C P_{t}=f\left[X_{1 t}, X_{2 t}, X_{3 t}, X_{4 t}, X_{5 t}\right.$ e $\left.X_{6 t}\right]$, sendo que, naturalmente, o relacionamento entre as variáveis, por definição, é dado pela soma, o que nos possibilita visualizar a função CP como sendo $C P_{t}=X_{1 t}+X_{2 t}+X_{3 t}+X_{4 t}+X_{5 t}+X_{6 t}$ e, portanto, $C P_{t}=\sum_{i=1}^{6} X_{i t}$.

Tal descritivo confere com o que foi verificado na revisão bibliográfica e, além disso, corrobora o que Lambert, Stock e Vantine (1998) preconizam relativamente aos componentes do ciclo do pedido.

Complementarmente, considerando-se que os dados obtidos são valores médios, ou seja, referem-se a estatísticas descritivas de tendência central, pode-se ajustar a função $\mathrm{CP}(\mathrm{t})$ para $\mathrm{cp}(\mathrm{t})$, da seguinte maneira:

$\mathrm{cp}_{\mathrm{t}}=X_{1 t}+X_{2 t}+X_{3 t}+X_{4 t}+X_{5 t}+X_{6 t}+u_{1}=\sum_{i=1}^{6} X_{i t}+u_{1}$,

onde $u_{1}$ representa o erro de estimativa de $\mathrm{cp}_{t}$, ou ainda, a parte de $\mathrm{cp}_{t}$ não explicada pela função mencionada, relativamente a cada observação t.

Observe-se que o escopo deste trabalho se concentra na análise de $X_{3}$, visto que é justamente nessa etapa que se verifica a realização do processo de análise de crédito.

Há basicamente duas formas de se avaliar o processamento do pedido, tendo em conta que $X_{3}$ poderia assumir diferentes amplitudes, dependendo da forma que seja utilizada para analisá-lo, o que acaba- rá influenciando a função CP (ciclo do pedido). Dessa forma tem-se:

(1) $\mathrm{CP}=f$ (qualidade das informações utilizadas para análise de crédito); ou

(2) $\mathrm{CP}=f$ (análise de crédito).

No primeiro caso, assume-se a premissa de que $X_{3}$ seja função direta da qualidade das informações, inclusive, as de caráter contábil, o que poderia significar uma diferença temporal no que tange à análise de um cliente A ou B, sendo A e B distintos, que, por sua vez, influenciaria CP. Na outra situação, considera-se $X_{3}$ como função direta apenas do processo de análise de crédito, o qual estaria influenciando CP.

Como neste estudo de caso, a Atofina Brasil se baseia na consideração de que há, normalmente, um auditor ou um contador responsável pela elaboração de tais demonstrações, bem como pelo conteúdo das mesmas, pode-se constatar que, como a análise de crédito está dentro do ciclo do pedido, conforme demonstrado na revisão bibliográfica, (2) é uma função sobrejetora ${ }^{7}$ e apresenta como tangente um valor positivo, isto é, $\operatorname{tg} C P_{X 1, X 2, X 3, X 4, X 5, \mathrm{X} 6}>0$ já que $\frac{\delta C P}{\delta t}>0$.

Verifica-se, assim, sob a abordagem (2) referida anteriormente, que a variável análise de crédito é componente da variável $X_{3}$, que é o processamento do pedido, onde $X_{3}$ pode ser decomposta, segundo Lalonde (1976), da seguinte forma:

$X_{3}=f\left[\begin{array}{l}\text { elementos de operação }\left(A_{1}\right) \\ \text { elementos de comunicação }\left(A_{2}\right) \\ \text { elementos de crédito }\left(A_{3}\right)\end{array}\right]$, donde se tem: $X_{3}=A_{1}+A_{2}+A_{3}=\sum_{i=1}^{3} A_{i}$, onde:

$A_{1}$ representa o tempo que compreende as atividades de verificação de disponibilidade do produto, escalonamento, preparação para a expedição e faturamento, os quais são os denominados de elementos de operação (ou elementos operacionais);

$A_{2}$ representa o período de tempo necessário às alterações no pedido, quando houver consulta sobre situação, localização e velocidade do deslocamento do pedido entre as áreas de responsabilidade envolvidas, correção de erros e pedidos de informações, que são as principais atividades de comunicação nesse processo, sendo, por isso, denominados de elementos de comunicação e, por fim, 
$A_{3}$ significa o tempo demandado para os elementos de crédito que se consubstanciam no processo de análise, estabelecimento e liberação de crédito.

Ademais, em condições caeteris paribus, quanto maior o tempo demandado para se fazer a análise das demonstrações contábeis, maior é o tempo da análise, estabelecimento e liberação do crédito e, aumentando, conseqüentemente, o tempo do processamento do pedido. Logo, nessas condições, maior será amplitude do ciclo do pedido.

Todavia, é necessário avaliar a função $A_{3}$ para se verificar se isso realmente ocorre no caso da Atofina Brasil. Esse trabalho se concentra justamente na análise da variável $A_{3}^{8}$ que pode ser decomposta da seguinte forma:

\section{$\operatorname{SCI}\left(Z_{1}\right)$ \\ $\operatorname{SERASA}\left(Z_{2}\right)$ \\ Mercado $\left(Z_{3}\right)$ \\ Demonstrações Contábeis $\left(Z_{4}\right)$}

$\operatorname{Setor}\left(Z_{5}\right)$

Pontualidade de pagamento junto à Atofina $\left(Z_{6}\right)$ $A_{3}=f$ Análise de recusa de liberações anteriores $\left(Z_{7}\right)$

Demora no recebimento de informações requeridas $\left(Z_{8}\right)$

Verificação dos resultados dos outputs do sistema e redação do documento necessário para estabelecimento do limite e liberação do crédito $(L)$

Assim, o modelo genérico da análise, estabelecimento e liberação de crédito seria:

$A_{3}=Z_{1}+Z_{2}+Z_{3}+Z_{4}+Z_{5}+Z_{6}+Z_{7}+Z_{8}+L=\sum_{i=1}^{8} Z_{i}+L$

Todavia, nos casos de primeira venda a prazo a um cliente são desconsideradas as variáveis $Z_{6} \mathrm{e}$ $Z_{7}$, dada a não aplicabilidade nessa situação específica. Isto se justifica pelo fato de que a pontualidade de pagamento junto à Atofina apenas poderia ser analisada no caso de haver um histórico do relacionamento comercial entre a Atofina e esse cliente. Por essa mesma razão, também não é possível verificar qualquer recusa de liberação anterior desse tipo de cliente.
Desse modo, o modelo específico para os casos de primeira venda a prazo realizada pela Atofina Brasil para seus clientes seria:

$A_{3}=Z_{1}+Z_{2}+Z_{3}+Z_{4}+Z_{5}+Z_{8}+L$

Procedendo-se a um ajuste do modelo específico pela média tem-se:

$A_{3}=\bar{Z}_{1}+\bar{Z}_{2}+\bar{Z}_{3}+\bar{Z}_{4}+\bar{Z}_{5}+\bar{Z}_{8}+L+u$, onde $u$ representa o erro da estimativa.

Contudo, pôde-se observar, no caso da Atofina, que $\bar{Z}_{1}, \bar{Z}_{2}, \bar{Z}_{4}$ e $\bar{Z}_{5}$ representam um tempo médio padrão. Isso se explica pelo fato de que no caso dessas variáveis, há de se considerar a padronização dos dados inseridos na planilha de análise de crédito e a habilidade média dos analistas de crédito. Ademais, levando-se em conta o fato de se ter todas as informações necessárias às análises de crédito disponíveis, $L$ não apresenta variabilidade significativa.

Por fim, considerando-se que, conforme dados obtidos em entrevista, o tempo médio esperado para análise de crédito, no caso de uma primeira venda a um cliente, é de 3 horas, tem-se:

$$
A_{3\left(1^{a} \text { venda }\right)}=3 h
$$

Porém, o limite aceitável para se proceder à análise de crédito é de 48 horas, conforme a política de crédito adotada pela Atofina Brasil. Assim, temos que:

$$
\text { máximo } A_{3\left(1^{a}\right. \text { venda) }}=48 \mathrm{~h}
$$

Ainda, deve-se levar em consideração que o atraso na análise, no estabelecimento e na liberação do limite de crédito é de, no máximo, dois dias, a contar daquelas 48 horas estabelecidas como tempo máximo, no caso de situações extremas, conforme mencionado no item 3.2.1, tal como a não colaboração de determinado fornecedor desse cliente para que a Atofina tenha acesso a determinadas informações num processo assemelhado à circularização, porém, não se concentrando na confirmação de saldos, mas buscando averiguar a pontualidade do cliente analisado junto a ele. Dessa maneira, poder-se-ia descrever a variável $A_{3}$ da seguinte forma:

$$
A_{3\left(1^{a} \text { venda }\right)}=(3 h, 96 h)
$$

Entretanto, como essa situação só se verifica em casos extremos, cuja freqüência absoluta ou relativa, conforme auferido em entrevista com o gestor de crédito da Atofina Brasil, é bastante baixa, pode-se considerar para fins de análise que $A_{3\left(1^{a} \text { venda }\right)}$ situa-se

${ }^{8}$ Todas as variáveis dessa equação referem-se ao tempo demandado para exercer cada uma das atividades envolvidas. 
no seguinte intervalo de valores $(3 h, 48 h)$, já que tais pontos de stress não apresentam influência significativa sobre as médias consideradas. Note-se que, apesar de a média ser uma medida que sofre influência de todos os valores de uma série considerada, o fato de a maior parte dos valores estarem concentrados em torno de um determinado valor e somente um estar distanciado desses, e, ainda, de essa distância não ser tão acentuada, a alteração esperada na média é de uma amplitude reduzida. Além disso, ao se completar essas 48 horas, a área comercial da Atofina Brasil acaba por tomar a frente da decisão de liberar ou não determinado montante de crédito para que o ciclo do pedido não seja prejudicado, o que vai justamente ao encontro da sua estratégia de ampliação de mercado, a qual foi descrita no estudo de caso.

Dessa maneira, a variabilidade da amplitude de $A_{3}$ decorre diretamente de $\bar{Z}_{3}, \bar{Z}_{8}$ e $L$, e não de $\bar{Z}_{4}$, já que não se despende tempo adicional na análise de crédito na questão da qualidade das informações contidas nas demonstrações contábeis, conforme foi possível constatar empiricamente.

Destarte, é correto inferir que a qualidade das demonstrações contábeis não apresenta influência temporal no ciclo do pedido.

Porém, foi possível constatar que isso se verifica em decorrência de o analista de crédito pressupor que as informações contábeis proporcionam um bom indicador da situação econômico-patrimonial da empresa, por serem elaboradas, pressupostamente, com base nos princípios contábeis geralmente aceitos e de serem auditadas ou pelo menos assinadas pelo contador da empresa cliente.

Assim, fica patente a importância da qualidade da informação contábil, posto que se elas não estiverem presentes, poderá o usuário dessas demonstrações (nesse caso, a Atofina Brasil) se defrontar com um viés significativo nas ponderações e conclusões do analista de crédito respectivo.

\section{CONSIDERAÇÕES FINAIS}

No caso específico da Atofina Brasil, pela análise da modelagem desenvolvida no tópico 4 , podese concluir que, independentemente da qualidade das informações contidas nas demonstrações contábeis, o tempo demandado no processo de análise, estabelecimento e liberação de crédito no caso de um cliente novo $\left(A_{3\left(1^{1} \text { venda }\right)}\right)$ varia dentro de um intervalo de $3 h$ a $48 h$, posto que a avaliação da qualidade da informação contábil por parte do analista de crédito não é uma atividade do processo de análise de crédito, por não estar em seu escopo de trabalho verificar se as qualidades da informação contábil estão ou não sendo consideradas na elaboração das demonstrações contábeis. $O$ analista de crédito tem por objetivo extrair das demonstrações contábeis índices financeiros para avaliar a capacidade econômico-financeira de seu cliente em uma relação de venda a prazo.

Cabe ressaltar que as qualidades básicas da informação contábil são necessárias para torná-la útil. No entanto, esse é um pressuposto que deve estar no escopo de trabalho do profissional de contabilidade para a elaboração da informação contábil e não do usuário da informação. Portanto, é natural que um analista de crédito exija informações de qualidade, mas não avalie tal parâmetro. Além disso, o parecer da auditoria ou a assinatura do contador são tomados pelo analista como uma garantia de confiabilidade de que a informação represente, adequadamente, em todos os aspectos relevantes, a situação econômico-financeira da empresa.

Logo, independentemente da qualidade das informações das demonstrações contábeis, o ciclo do pedido permanecerá praticamente o mesmo, se todas as outras variáveis forem mantidas constantes. A única variabilidade no ciclo do pedido decorrente de $A_{3}$ corresponde justamente à amplitude de $45 \mathrm{~h}$ (48h-3h), que, no caso, não está atrelado a $Z_{4}$, mas $\operatorname{sim} a Z_{3}$ e $Z_{8}$.

Tal constatação se contrapõe à hipótese geral estabelecida dessa pesquisa, de que a análise das demonstrações contábeis utilizadas na atividade de estabelecimento do limite de crédito poderia influenciar no ciclo do pedido, de modo que poderia aumentálo de forma significativa, pois relativamente à abordagem (2) explicitada no tópico 4, que se baseia em medida temporal, pode-se verificar que o tempo de análise das demonstrações contábeis não apresenta impacto significativo em CP (ciclo do pedido).

Deve-se esclarecer que o fato de a qualidade da informação contábil não exercer influência temporal no ciclo do pedido nesse caso específico, não signifi- 
ca que as qualidades básicas da informação contábil não exerçam influência na qualidade da decisão do analista de crédito. Todavia, não foi escopo deste trabalho verificar de que forma isso ocorre, ficando como uma das sugestões para estudos posteriores.

De fato, verifica-se que, se levada em considera- ção a abordagem (1) do item 4 é direta a inferência de que a qualidade das demonstrações contábeis exercem papel de crucial importância no processo de análise de crédito, porém, a mensuração desse impacto na tomada de decisão do analista de crédito fica como proposta para estudos posteriores.

\section{BIBLIOGRAFIA}

BALLOU, Ronald H. Gerenciamento da Cadeia de Suprimentos: planejamento, organização e logística empresarial. Tradução Elias Pereira. 4. ed. Porto Alegre: Bookman, 2001.

Logística Empresarial: transportes, administração de materiais e distribuição física; tradução Hugo T. Yoshizaki, São Paulo: Atlas, 1993.

BOWERSOX, Donald J.; CLOSS, David J. Logistical management: the integrated supply chain process. McGrawHill, 1996. [S.L.].

CAOUETTE, John B.; ALTMAN, Edward I.; NARAYANAN, Paul. Gestão do Risco de Crédito: o próximo grande desafio financeiro. Tradução de Allan Hastings; revisão técnica João Carlos Douat. Rio de Janeiro: Qualitymark, 1999.

CHRISTOPHER, Martin. Logística e gerenciamento da cadeia de suprimento. 1.ed. São Paulo: Pioneira, 1997.

ESPÍRITO SANTO, Angélica do. Considerações sobre o papel das demonstrações contábeis no processo de estabelecimento de limites de crédito, como parte do processamento de pedidos. 2003. Dissertação (Mestrado em Controladoria e Contabilidade) - Faculdade de Economia, Administração e Contabilidade, Universidade de São Paulo.

GAMBLE, Richard H. Map of Minefield. Business Credit. July/ August 2002. [S.L.].

GIL, Antônio Carlos. Técnicas de pesquisa em economia e elaboração de monografias. 3.ed., São Paulo: Atlas, 2000.

IEZZI, Gelson; MURAKAMI, Carlos. Fundamentos da Matemática Elementar. Vol.1, Atual Editora, 7 ed., 1995, p. 7-9. [S.L.].
IKEDA, R. H. Metodologias de Avaliação de Tracking Errors na Gestão Passiva de Fundos de Investimento. Uma Discussão sob o Prisma da Governança Corporativa e do Objetivo Fundamental da Contabilidade. 2002. Dissertação (Mestrado em Controladoria e Contabilidade) - Faculdade de Economia, Administração e Contabilidade, Universidade de São Paulo.

IUDíCIBUS, Sérgio de. Teoria da Contabilidade. 5. ed., São Paulo: Atlas, 1997.

LALONDE, Bernard J.; ZINSZER, Paul H. Customer Service: Meaning and Measurement. Chicago National Council of Physical Distribution Management, 1976, p. iv.

LAMBERT, Douglas M., STOCK, James R., VANTINE, J. G. Administração Estratégica de Logística. São Paulo: Vantine Consultroria, 1998.

RUTNER, Stephen M., LANGLEY, John C. Jr. Logistics Value: Definition, Process and Measurement. The International Journal of Logistics Management. Vol 11, N.2, 2000, p. 73-82.

SCHRICKEL, Wolfgang Kurt. Análise de crédito: concessão e gerência de empréstimos. 5. ed., São Paulo: Atlas, 2000.

SECURATO, José Roberto. Crédito - Análise e Avaliação do Risco. São Paulo: Saint Paul Institute of Finance, 2002.

SILVA, José Pereira da. Gestão e Análise de Risco de Crédito. 3. ed., São Paulo: Atlas, 2000.

YIN, Robert K. Case study research: design and methods. Rev. ed. Newbury Park, Calif.: Sage (Mestrado em Controladoria e Contabilidade) - Faculdade de Economia, Administração e Contabilidade, Universidade de São Paulo. Publications, 1989.

NOTA:

Endereço da autora:

ANGÉLICA DO ESPÍRITO SANTO

Rua do Livramento,66 Bloco A - $1^{\circ}$ andar -lbirapuera

04008-030 - São Paulo - SP 